\title{
Chronic lymphoglandular enlargement and toxoplasmosis in children
}

\author{
T. THOMAIDIS, K. ANASTASSEA-VLACHOU, C. MANDALENAKI-LAMBROU, \\ C. THEODORIDIS, AND E. VRAHNOU
}

From the First Department of Paediatrics, Athens University, Greece

SUMMARY Serum antitoxoplasma titres were determined simultaneously by the direct agglutination and the indirect immunofluorescent tests in 52 children aged 2 to 16 years having chronic lymph node enlargement, mainly cervical. Direct agglutination titres were raised (64 to 4096) in 22 children $(42 \%)$, but rarely in the control groups of children with acute suppurative lymphadenitis, and healthy children, adults, nurses, and physicians. It is concluded that toxoplasmosis is commoner in Greek children than previously believed, and that it should be included in the differential diagnosis of lymphoglandular enlargement. Clinically the condition is mild and may be self-limited, but it should be treated promptly with trimethoprim-sulphamethoxazole, in order to prevent reactivation in adult life.

Toxoplasmosis is an infection which is highly variable in its clinical manifestations; these include congenital, ocular, disseminated, encephalomyelitic, epidemic, febrile lymphoglandular, oligosymptomatic lymphoglandular, and asymptomatic forms (Ghorbani and Samii, 1973; Huggins, 1973; Huziak et al., 1974). The lymphoglandular form is mainly encountered in adults, who usually are severely affected with fever and general toxicity. In addition, there is swelling of the neck glands, and sometimes of other lymph glands. Recently attention has been drawn to the possibility that some $15 \%$ of mild and chronic lymphadenopathy of undetermined aetiology may be due to toxoplasmosis (WHO, 1969). We report the results of a study of the relationship of toxoplasmosis and chronic lymphadenopathy in Greece. Serum antibody against Toxoplasma gondii was measured simultaneously by two methods in 52 children with chronic or subacute lymphoglandular enlargement. Antibody was also measured in children with acute suppurative lymphadenitis, normal children, adults, and hospital personnel, who served as controls.

\section{Patients}

52 children with lymphoglandular enlargement were selected from the outpatients and inpatients of the 1st Department of Paediatrics, Athens University within a period of 2 years. The criteria for selection

Received 12 September 1976 were the following. (a) Enlargement of multiple lymph glands (minimum 3) of 1 to $8 \mathrm{~cm}$ in diameter, not adherent to each other and painless. (b) Absence of signs of suppuration or acute inflammation such as pain, redness, fluctuation, or oedema of surrounding tissues. (c) Duration of enlargement of more than 3 weeks. (d) Distribution of lymph glands multifocal or in one region. (e) Therapy with oral penicillin, ampicillin, or erythromycin ineffective. Some of these patients were re-examined clinically and serologically after 1 month and one after 1 year.

Controls. (a) 23 age-matched children with acute suppurative lymphadenitis mainly in the cervical region; (b) 10 age-matched children, who were brought to the orthopaedic clinic for change of plaster casts, 6 who were otherwise healthy; (c) 10 healthy adults; (d) 21 healthy nurses; (e) 14 healthy physicians.

\section{Methods}

Antitoxoplasma serum titres were determined in all 52 patients by the direct agglutination test (Fulton and Turk, 1959; Couzineau and Baufine-Ducrocq, 1970) and the indirect IgM/IgG immunofluorescent test (Garin and Ambroise-Thomas, 1963; AmbroiseThomas et al., 1966). Sera from controls were examined by the direct agglutination test only. The dye test as used in the UK, is carried out in Greece at the Institut Pasteur, Athens; the latter serving as a central laboratory. We have recently introduced 403 
the direct agglutination test, which is comparable to the dye test, is equally sensitive, simpler, and less expensive. At the beginning of the study, 10 sera were also examined by the dye test, which gave similar results.

Direct agglutination was conducted on a Linbro IS MVC 96 plate having wells with a conical bottom. Twofold serial dilutions of serum were prepared. Formolized toxoplasma suspension was obtained from B.D. Merieux Company. Agglutination was shown by a diffuse lawn of parasites or an irregularly shaped button, while a clearly defined button represented a negative reaction. The highest dilution of the serum which produced disruption of the button with an irregular periphery was taken as the end point.

For the indirect immunofluorescent test, lyophilized and optimally resuspended toxoplasma were placed on glass slides at various spots. Serum dilutions of $1 / 20,1 / 200$, and twofold serial dilutions from $1 / 1000$ were placed on the parasite smears and left to incubate in a wet chamber at $37^{\circ} \mathrm{C}$. For detecting antitoxoplasma immunoglobulin, fluorescein-conjugated antihuman immunoglobulin diluted in 1:10 000 Evans blue solution was added on the parasite smear spots. The titre of the test serum was taken as the highest dilution which produced bright complete peripheral fluorescence in the majority of the parasites in several fields of the smear. Toxoplasma and reagents were obtained from B.D. Merieux. Titres were expressed as the reciprocal of the dilution of the end point.

\section{Results}

The results of the serological tests from children with chronic lymphoglandular enlargement are shown in the Fig. and Tables 1-3. 22 children out of 52 (42\%) had direct agglutination titres ranging from 64 to 4096, i.e. diagnostic for toxoplasmosis. In 19 children agglutination titres were 16 or below, indicating probable past infection. The remaining 11 children were not considered, since the agglutination titre was 32. The last is not diagnostic by itself and repeat examinations were not done. Corresponding immunofluorescent titres coincided approximately, since a difference of one dilution is within laboratory error (Tables 1-3).

Results from the control group were as follows. Of 23 children with acute suppurative lymphadenitis, in 2 the agglutination titre was 32 and in one 64 . Of 10 normal children, one had a titre of 64 , and of 10 normal adults 2 had titres of 32 and 128, respectively. In the group of physicians there were more individuals with titres higher than 16 (Fig.).

Children with glandular toxoplasmosis were separated into two groups : (a) 14 recently affected, i.e. 1 month before serological examination (Table 1), and (b) 8 children examined within a period from 2 to 12 months after the onset of disease (Table 2). Titres were higher in children of group (b), who also gave a story of remissions and exacerbations of their symptoms. Clinical findings were generally not severe, and severity did not correlate with the titres in either group. Fever and malaise were present in only

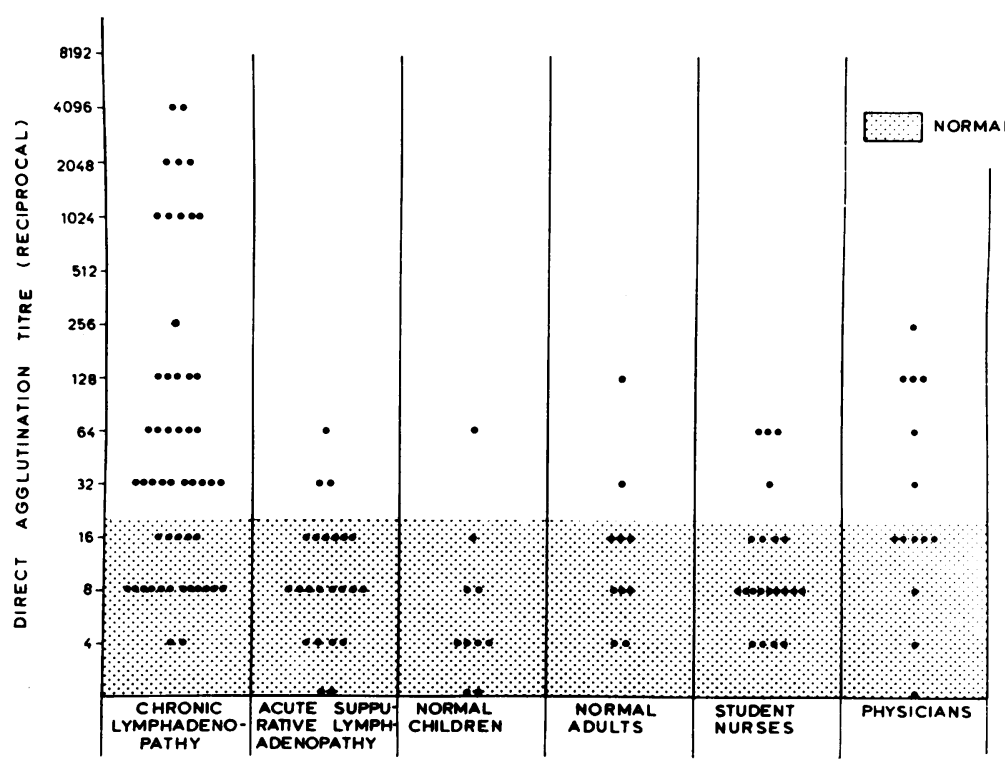

Fig. Each - represents one determination in each case. 
Table 1 Serum antibody titres in children with recent lymphoglandular toxoplasmosis

\begin{tabular}{llll}
\hline & & \multicolumn{2}{l}{ Tests } \\
\cline { 3 - 4 } Case no. & Age (years) & Agglutination & Immunofiuorescence \\
\hline 1 & 7 & 4096 & 64000 \\
2 & 4 & 2048 & 32000 \\
& & $1024^{*}$ & 16000 \\
3 & 6 & 1024 & 8000 \\
& & $512^{*}$ & 8000 \\
4 & 15 & 256 & 8000 \\
5 & 81 & $1024^{*}$ & 32000 \\
6 & 5 & 256 & 4000 \\
7 & $6 \frac{1}{2}$ & 128 & 8000 \\
8 & 4 & 128 & 4000 \\
9 & 5 & 128 & 8000 \\
& & 64 & 4000 \\
10 & $6 \frac{1}{2}$ & $128^{*}$ & 8000 \\
11 & 5 & 64 & 1000 \\
12 & 7 & 64 & 4000 \\
13 & $2 t$ & 64 & 4000 \\
14 & 4 & 64 & 2000 \\
& & 64 & 2000 \\
\hline
\end{tabular}

*Titre of examination done after 3 weeks.

Table 2 Serum antibody titres in children with lymphoglandular toxoplasmosis of more than 1 month's duration

\begin{tabular}{|c|c|c|c|c|}
\hline \multirow[b]{2}{*}{$\begin{array}{l}\text { Case } \\
\text { no. }\end{array}$} & \multirow[b]{2}{*}{$\begin{array}{l}\text { Age } \\
\text { (years) }\end{array}$} & \multirow[b]{2}{*}{$\begin{array}{l}\text { Duration } \\
\text { (m) }\end{array}$} & \multicolumn{2}{|l|}{ Tests } \\
\hline & & & Agglutination & Immunofluorescence \\
\hline 15 & 5 & 6 & 4096 & 64000 \\
\hline 16 & 12 & 8 & 2048 & 32000 \\
\hline 17 & 7 & 12 & 2048 & 16000 \\
\hline 18 & 16 & 9 & 1024 & 32000 \\
\hline 19 & 13 & 12 & $\begin{array}{l}1024 \\
1024^{*}\end{array}$ & $\begin{array}{l}32000 \\
32000\end{array}$ \\
\hline 20 & 5 & 10 & $\begin{array}{c}512 \\
1024^{*}\end{array}$ & $\begin{array}{l}16000 \\
32000\end{array}$ \\
\hline 21 & 2 & 6 & $\begin{array}{r}128 \\
4^{*}\end{array}$ & $\begin{array}{r}2000 \\
20\end{array}$ \\
\hline 22 & 12 & 2 & $\begin{array}{l}64 \\
32 *\end{array}$ & $\begin{array}{l}4000 \\
2000\end{array}$ \\
\hline
\end{tabular}

*Titre of examination done after 3 weeks

Table 3 Antitoxoplasma serum titres in a representative sample of children with chronic lymphadenitis of unknown aetiology

\begin{tabular}{llll}
\hline & \multicolumn{3}{l}{ Tests } \\
\cline { 3 - 4 } $\begin{array}{l}\text { Age } \\
\text { (years) }\end{array}$ & $\begin{array}{l}\text { Duration } \\
(m)\end{array}$ & Agglutination & Immunofluorescence \\
\hline 4 & 24 & 16 & 1000 \\
6 & 24 & 16 & 200 \\
7 & 1 & 8 & 1000 \\
4 & 8 & 8 & 20 \\
2 & 1 & 8 & 200 \\
$2 \frac{1}{7}$ & 12 & 4 & 20 \\
7 & 5 & 4 & 20 \\
7 & 5 & 0 & 20 \\
\hline
\end{tabular}

5 children in both groups. The spleen was slightly enlarged in 5 children, 3 of whom had systemic manifestations. Glandular enlargement usually involved the cervical lymph glands, anterior or posterior, or the supraclavicular; less frequently the axillary and/or the inguinal; rarely the mandibular and suboccipital glands were enlarged. The size of the lymph glands was most commonly 3 to $4 \mathrm{~cm}$, and up to $8 \mathrm{~cm}$ as a maximum. In one child there was also mild enlargement of mediastinal lymph glands, as seen by $x$-ray, which regressed after therapy.

Almost all the children had a normal white blood count, but a few had a mild lymphocytosis. Lymph gland puncture was attempted in only 3 children and biopsy in 2. The latter examination showed changes compatible with toxoplasmosis, i.e. follicular hyperplasia and aggregates of epithelioid histiocytes. One child had in addition to toxoplasmosis active brucellosis (Table 1, Case 2).

In the majority of cases trimethoprim-sulphamethoxazole was administered for a period of 3 weeks. Only 14 children were brought for follow-up, 8 of whom were re-examined serologically (Tables 1 , 2). By chance, 2 children were not treated: in one of these the titre remained high, whereas clinical findings disappeared. In general, glandular enlargement started to regress one week after treatment and disappeared completely by the end of the $3 \mathrm{rd}$ week. The only child who was re-examined 1 year later had lost the glandular enlargement, but the titre remained at 1024 (Table 2, Case 5), but he was allegedly still eating undercooked meat.

Concerning the mode of transmission, 6 children coming from rural districts were in contact with cats (Greeks do not commonly keep pet animals). For the 11 children with a titre of 32 no conclusions can be drawn. In 2 of these cases whose condition warranted biopsy of a lymph gland, Hodgkin's disease was queried in one and reticulum cell sarcoma established in the other. On the other hand, children with chronic lymphadenopathy and negative serological tests (Table 3, Fig.), differed in no clinical respect from those having toxoplasmosis, except that enlargement involved the cervical lymph glands more frequently.

\section{Discussion}

Glandular toxoplasmosis is not uncommon throughout the world (Ghorbani and Samii, 1973), including South-East Europe (Huziak, 1974), but reports usually concern young adults and only rarely adolescents or children. The first large series from Greece in adults and a few adolescents (50 patients) was recently published (Tzamouranis, 1975). In France 
where meat is often consumed undercooked or even raw, toxoplasmosis has repeatedly been described in all its forms in children (Dupoirieux and Jeanne, 1972), but a large series of the glandular form in children has not been previously reported.

Diagnosis of toxoplasmosis is not always simple, but is usually established by histological or serological means. Histological changes in lymph glands are distinctive and enable a confident diagnosis to be made (Dorfman and Remington, 1973). The only two biopsies in our series both showed changes compatible with toxoplasmosis.

High serum antibody titres in the presence of symptoms denote active disease, whereas a moderate titre may indicate regression or exacerbation. In the latter case a fourfold increase in titre 3 to 4 weeks later may give the answer, but repetition of serological tests is not always feasible in mild cases. In general high titres frequently persist for about 2 months, but occasionally they may persist for several years as in one of our cases quoted (Desmonts et al., 1973; Karim and Ludlam, 1975).

Both the serological methods we used measure similar antibodies, i.e. those against cell-wall antigen (Karim and Ludlam, 1975). A 'strongly positive' result is usually accepted with a direct agglutination titre of 512 and an immunofluorescent titre of 2000. But Couzineau et al. (1973) considered that a direct agglutination titre of 64 should not be discounted. By this method both IgM and IgG antibodies are measured, so that a titre of 64 at an early stage of the disease represents IgM antibody, and is significant. During the course of the disease this test may show a fall and subsequent second rise in titre, as IgM antibody decreases and IgG increases. Several authors propose as adequate for epidemiological studies the determination of the titre from a single specimen by two methods simultaneously (Desmonts et al., 1972, 1973; Couzineau et al., 1973).

The Fig. shows that very few of the controls gave negative results. Titres of 8 and 16 may well represent past infection; titres above 32 probably are asymptomatic cases, as concluded from other studies (Huggins, 1973; Schassan et al., 1974; Husiak et al., 1974).

From the present study we conclude that toxoplasmosis is a common cause of chronic glandular enlargement in Greek children, and that the direct agglutination test is a simple and reliable means of diagnosis. The clinical course in children is milder than that described in adults (Jones et al., 1965; Kean et al., 1969). The condition occurs as early as 2 years of age and may improve without treatment, but should be treated promptly, as therapy is most effective when given in the early stages of the disease. Treatment with trimethoprim- sulphamethoxazole was very effective, as found by others (Meyer, 1974). In 2 children of our series with chronic glandular enlargement, who had titres of 32, biopsies showed neoplasia of the lymphatic system, indicative perhaps of reactivation of latent toxoplasmosis secondary to immunosuppression (Carey et al., 1973).

The cat as the definitive host is the main reservoir and is contaminating man and meat-producing animals, who in turn contaminate man through consumption of their meat (Saari and Räisänen, 1974). In Greece, cats are infrequently kept in urban homes, and therefore undercooked meat must be considered as a possible source of infection of children. Undercooked meat is not a traditional form of food in Greek homes in and around Athens where most of our patients come from. But 'Shish kebab', an inexpensive barbecued mixed pork and beef widely consumed in standing luncheonettes and loved by children, could perhaps be responsible (especially when queues are long!)

\section{References}

Ambroise-Thomas, P., Garin, J. P., and Rigaud, A. (1966). Amélioration de la technique d'immunofluorescence par l'emploi de contre-colorants. Application aux toxoplasmes. Presse Médicale, 74, 2215-2216.

Carey, R. M., Kimball, A. C., Armstrong, D., and Lieberman, R. H. (1973). Toxoplasmosis. Clinical experiences in a cancer hospital. American Journal of Medicine, 54, 30-38.

Couzineau, P., and Baufine-Ducrocq, H. (1970). Agglutination directe des toxoplasmes. Annales de Biologie Clinique, 28, 411-415.

Couzineau, P., Baufine-Ducrocq, H., Peloux, Y., and Desmonts, G. (1973). Le sérodiagnostic de la toxoplasmose par agglutination directe. Nouvelle Presse Médicale, 2, $1604-1606$.

Desmonts, G., Couvreur, J., Colin, J., and Peupion, J. (1972). Vers un diagnostic précose de la toxoplasmose aigüe. Etude critique du test de Remington. Nouvelle Presse Médicale, 1, 339-342.

Desmonts, G., Niel, G., Gentilini, M., and Couvreur, J. (1973). Standardisation du séro-diagnostic de la toxoplasmose. Nouvelle Presse Médicale, 2, 1601-1603.

Dorfman, R. F., and Remington, J. S. (1973). Value of lymph-node biopsy in the diagnosis of acute acquired toxoplasmosis. New England Journal of Medicine, 289, 878-881.

Dupoirieux, J., and Jeanne, L. (1972). A propos de la toxoplasmose. Difficultés et incertitude du diagnostic. Remarques sur quelques observations. Semaine des Hôpitaux de Paris, 48, 3123-3127.

Fulton, J. D., and Turk, J. L. (1959). A direct agglutination test for Toxoplasma gondii. Lancet, 2, 1068-1069.

Garin, J. P., and Ambroise-Thomas, P. (1963). Le diagnostic sérologique de la toxoplasmose par la méthode des anticorps fluorescents (technique indirecte). Presse Médicale, 71, 2485-2488.

Ghorbani, M., and Samii, A. H. (1973). Toxoplasmic lymphadenitis in Iran. Journal of Tropical Medicine and Hygiene, 76, 158-160. 
Huggins, D. (1973). Toxoplasmose adquiride forma linfoglandular. Relato de 22 casos. Anais do Instituto de Higiene e Medicina Tropical(Lisbon), 1, 25-30.

Huziak, T., Fiser, D., Petrak, M., and Krsnjavi, B. (1974). Osservazione di alcuni casi di toxoplasmosi acquisita. Cenno clinico epidemiologico. Gionarle di Malattie Infettive e Parassitarie, 26, 815-819.

Jones, T. C., Kean, B. H., and Kimball, A. C. (1965). Toxoplasmic lymphadenitis. Journal of the American Medical Association, 192, 1-5.

Karim, K. A., and Ludlam, G. B. (1975). The relationship and significance of antibody titres as determined by various serological methods in glandular and ocular toxoplasmosis. Journal of Clinical Pathology, 28, 42-49.

Kean, B. H., Kimball, A. C., and Christenson, W. N. (1969). An epidemic of acute toxoplasmosis. Journal of the American Medical Association, 208, 1002-1004.

Meyer, A. (1974). Le meilleur traitement de la toxoplasmose. Nouvelle Presse Médicale, 3, 1383.
Saari, M., and Räisänen, S. (1974). Transmission of acute toxoplasma infection. The survival of trophozoites in human tears, saliva and urine and in cow's milk. Acta Ophthalmologica, 52, 847-852.

Schassan, H. H., Matz, K., Freisenhausen, H. D., and Harm, K. (1974). Contribution to the epidemiology and therapy of toxoplasmosis. I. Clinical and epidemiological aspects of toxoplasmosis. Infection, 2, 7-11.

Tzamouranis, N. (1975). Toxoplasmic lymphadenitis. Analysis of 50 cases. Communication at a Panhellenic Medical Meeting (Greece).

World Health Organization (1969). Toxoplasmosis. Technical Report Series No. 431. WHO, Geneva.

Correspondence to Dr. T. Thomaidis, Department of Paediatrics, 'Aghia Sophia' Children's Hospital, Athens 608, Greece. 